Marquette University

e-Publications@Marquette

$10-2012$

\title{
Cusp Catastrophe Models for Cognitive Workload and Fatigue in a Verbally Cued Pictorial Memory Task
}

\author{
Stephen J. Guastello \\ Marquette University, stephen.guastello@marquette.edu \\ Henry Boeh \\ Marquette University \\ Michael Schimmels \\ Marquette University \\ Hillary Gorin \\ Marquette University \\ Samuel Huschen \\ Marquette University
}

See next page for additional authors

Follow this and additional works at: https://epublications.marquette.edu/psych_fac

Part of the Psychology Commons

\section{Recommended Citation}

Guastello, Stephen J.; Boeh, Henry; Schimmels, Michael; Gorin, Hillary; Huschen, Samuel; Davis, Erin; Peters, Natalie E.; Fabisch, Megan; and Poston, Kirsten, "Cusp Catastrophe Models for Cognitive Workload and Fatigue in a Verbally Cued Pictorial Memory Task" (2012). Psychology Faculty Research and Publications. 219.

https://epublications.marquette.edu/psych_fac/219 


\section{Authors}

Stephen J. Guastello, Henry Boeh, Michael Schimmels, Hillary Gorin, Samuel Huschen, Erin Davis, Natalie E. Peters, Megan Fabisch, and Kirsten Poston 
Marquette University

e-Publications@Marquette

\section{Department of Psychology Faculty Research and Publications/College of Arts and Sciences}

This paper is NOT THE PUBLISHED VERSION.

Access the published version at the link in the citation below.

Human Factors, Vol. 54, No. 5 (October 2012): 811-825. DOI. This article is (C) Human Factors and Ergonomics Society and permission has been granted for this version to appear in e-

Publications@Marquette. Human Factors and Ergonomics Society does not grant permission for this article to be further copied/distributed or hosted elsewhere without the express permission from Human Factors and Ergonomics Society.

\section{Cusp Catastrophe Models for Cognitive Workload and Fatigue in a Verbally Cued Pictorial Memory Task}

\section{Stephen J. Guastello}

Professor of Psychology at Marquette University in Milwaukee, Wisconsin

PhD in Industrial-Organizational Psychology from the Illinois Institute of Technology in Chicago

Henry Boeh

Graduate Student in Clinical Psychology at Marquette University in Milwaukee Wisconsin

BA from Gustavus Adolphus College

Michael Schimmels

Graduate Student in Human Resources at Marquette University

BA in Psychology from Marquette University with Majors in Psychology, Neuroscience, and Classics

Hillary Gorin

Undergraduate Student at Marquette University Majoring in Psychology 


\section{Samuel Huschen}

Undergraduate Student at Marquette University Majoring in Psychology

\section{Erin Davis}

Graduate Student in Human Factors Engineering at Tufts University in Medford, Massachusetts BS from Marquette University with a Major in Biomedical Engineering

\section{Natalie E. Peters}

Undergraduate Student at Marquette University Majoring in Psychology

\section{Meghan Fabisch}

Undergraduate Student at Marquette University Majoring in Psychology

\section{Kirsten Poston}

Undergraduate Student at Marquette University Majoring in Psychology

\section{Abstract \\ Objective:}

The aim of this study was to evaluate two cusp catastrophe models for cognitive workload and fatigue.

They share similar cubic polynomial structures but derive from different underlying processes and contain variables that contribute to flexibility with respect to load and the ability to compensate for fatigue.

\section{Background:}

Cognitive workload and fatigue both have a negative impact on performance and have been difficult to separate. Extended time on task can produce fatigue, but it can also produce a positive effect from learning or automaticity.

\section{Method:}

In this two-part experiment, 129 under-graduates performed tasks involving spelling, arithmetic, memory, and visual search.

Results:

The fatigue cusp for the central memory task was supported with the quantity of work performed and performance on an episodic memory task acting as the control parameters. There was a strong linear effect, however. The load manipulations for the central task were competition with another participant for rewards, incentive conditions, and time pressure. Results supported the workload cusp in which trait anxiety and the incentive manipulation acted as the control parameters.

\section{Conclusion:}

The cusps are generally better than linear models for analyzing workload and fatigue phenomena; practice effects can override fatigue. Future research should investigate multitasking and task sequencing issues, physical-cognitive task combinations, and a broader range of variables that contribute to flexibility with respect to load or compensate for fatigue. 
Applications:

The new experimental medium and analytic strategy can be generalized to virtually any real-world cognitively demanding tasks. The particular results are generalizable to tasks involving visual search.

\section{Keywords}

cognitive workload, fatigue, memory, incentives, cusp catastrophe, buckling, anxiety

\section{Introduction}

In this article, we propose and test two theoretical models for understanding and separating the effects of cognitive workload and fatigue in response to several entangled problems. First, time pressure and workload stress contribute to a decline in performance (Conrad, 1951; Hendy, Liao, \& Milgram, 1997). Second, the conceptual and practical separation of the effects of workload and fatigue remains challenging (Ackerman, 2011; Guastello, Boeh, Shumaker, \& Schimmels, 2011; Hancock \& Desmond, 2001). Third, prolonged work periods can induce a practice effect while the work period is also setting the stage for fatigue (Guastello, 1995); a viable theory of cognitive workload and fatigue should separate these counteracting forces also. Fourth, the upper limits to channel capacity have been explained by both the presence of fixed or variable limits (Kantowitz, 1985).

A partial explanation, however, is that the decrement in performance that occurs when two or more tasks are performed simultaneously will depend on whether the tasks draw on the same perceptual, cognitive, or psychomotor resources (Wickens, 2008). Another partial explanation favoring variable upper limits involves coping or resilience (Hancock \& Warm, 1989; Harris, Hancock, \& Harris, 2005; Hockey, 1997; Matthews \& Campbell, 2009; Sheridan, 2008), but these processes are not sufficiently well defined yet. According to Lorist and Faber (2011), people working in fatigue conditions often respond by slowing down their output, that is, reducing speed stress. Ralph, Gray, and Schoelles (2010) likened the phenomenon to squeezing a balloon: Constraints in one place produce stretching in another place, but one cannot predict exactly where in advance; eventually, too much constriction pops the balloon. Furthermore, Alves and Kelsey (2010) observed that breaking the monotony of a fatiguing task with a more complicated task can reduce fatigue.

A possible solution to the cluster of problems takes the form of two catastrophe models for the effect of workload on performance and the effects of fatigue (Guastello, 2003; Guastello et al., 2011). The models, which are described next, have similar structures that portray performance changes over time, but they derive from different underlying dynamics. Contributing variables play different roles in each model. The use of the two models in a sufficiently complex experimental design permits the separation of cognitive workload and fatigue effects on performance. The principle of degrees of freedom is then introduced as part of the explanation for why the models work the way they do and provides a basis for explaining how system behavior could resemble the balloon metaphor. The new experiment assesses the models for a verbally cued pictorial memory task and provides some illustration of how the degrees-of-freedom principle could be operating in an episodic memory task. 


\section{Cusp Catastrophe Structural Model}

According to the classification theorem (Thom, 1975), all discontinuous changes of events can be modeled by one of seven elementary topological models (with qualifications). The models describe change among qualitatively distinct forms for behavior. The elementary catastrophe models are hierarchical and vary in the complexity of the behavior spectra they encompass. Changes in behavior are described by differential equations that represent the structure of the behavior spectrum, or response surface. The cusp model (Figure 1) is one of the simpler catastrophe models and the one that is most frequently used. The cusp response surface is three-dimensional and describes changes between two stable states of behavior (attractors). The two attractors are separated by a bifurcation structure (manifold). The shaded region of the response surface represents a region where very few points (e.g., behaviors of people) are likely to fall.

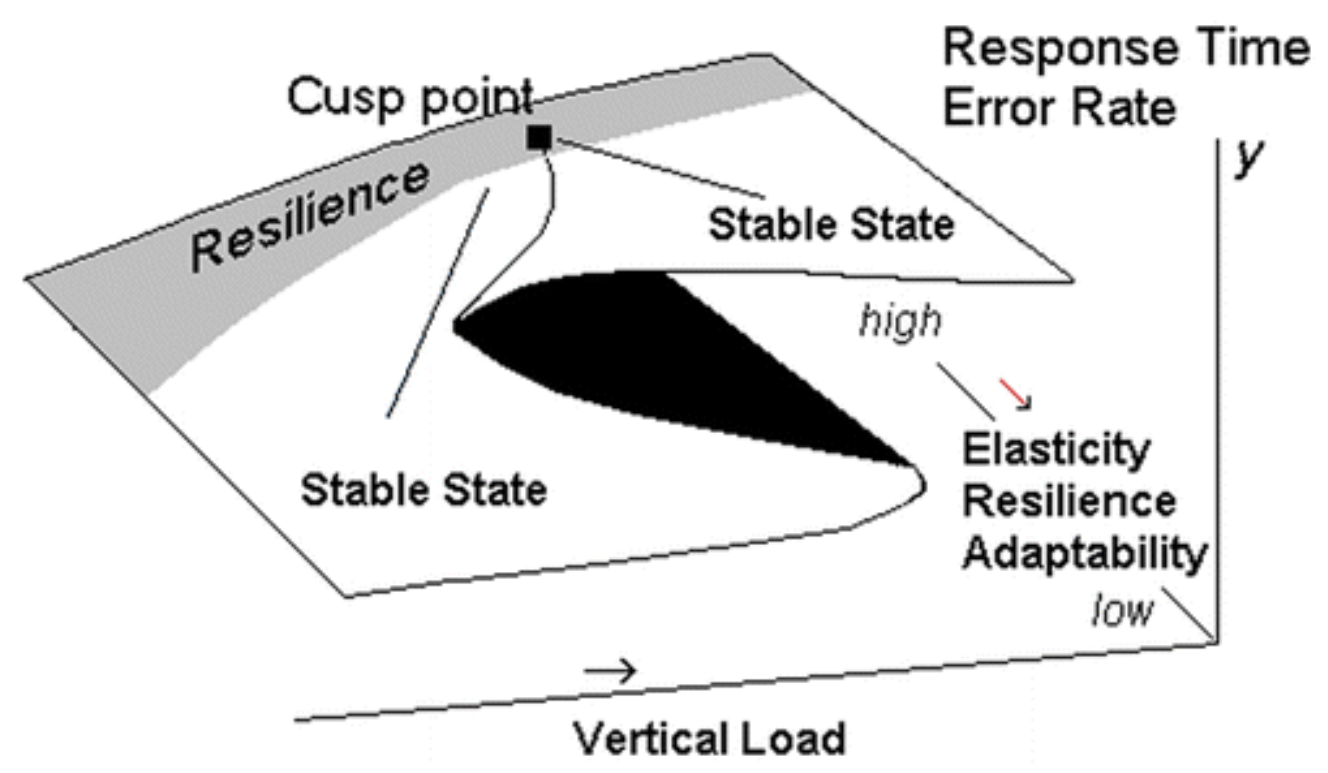

Figure 1. Two stable states of work performance as a function of elasticity (resilience) and workload.

The movement of points within the system is governed by two control parameters. Control parameters are essentially independent variables, with the important difference that they can act in ways that are more unique than the simple additive relationships that are found in linear models. The asymmetry parameter governs how close the system is to a discontinuous change in behavior. Imagine that the behavior of the system begins at the lower stable state of the response surface. If the asymmetry variable changes, no change in the behavior of the system is observed until a critical point is reached, when behavior changes suddenly. Behavior can change in the reverse direction, and again, the behavior of the system does not change whereas the asymmetry variable is changing until a different critical point is reached.

The bifurcation parameter governs how large the change will be. For high values of the bifurcation variable, change is discontinuous as the system changes from one stable state to another. For low values of the bifurcation variable, change is gradual, and the resulting behavioral states are not stable. 
The cusp point represents the region of greatest instability: The system can move to one of the stable states, with just a little deflection from the control parameters, or it could remain in the unstable area and display gradual changes in either direction. Importantly, the obvious discontinuous change events are part of the continuities that hold the spectrum of possible behavioral outcomes together.

The equation of the cusp response surface for a process that changes over time is

$$
d y / d t=y 3-b y-a, d y / d t=y 3-b y-a
$$

where $y$ is the dependent measure, $b$ is the bifurcation variable, and $a$ is the asymmetry variable. Equation 1 serves as the basis for evaluating the degree to which data fit the model in the most literal sense. The polynomial regression method is perhaps the most intuitively appealing method of doing so, although it is limited to situations in which the dependent measure is evaluated at (a minimum of) two points in time. The procedure is described in the Method section along with its logic of hypothesis testing.

The cusp catastrophe models for cognitive workload and fatigue are described next. The workload model was derived initially from the buckling dynamics of an elastic beam. The fatigue model was initially derived from the analysis of work performance curves for physical labor. Both are extended to cognitive work contexts here.

\section{Buckling Model for Workload}

The model for cognitive workload invokes the concept of Euler buckling (Zeeman, 1977). A piece of material that is subjected to sufficient amounts of stress in the form of repeated stretching will show a certain amount of deformity, or strain. Rigid materials will break, whereas flexible materials will rebound. The amount of permanent deformity induced by stress is the stress-strain ratio. Imagine a beam of relatively stiff material that is pin-jointed at both ends. Place a weight on the beam. If the material is rigid, and the weight is not supercritical, the beam will not buckle. When the weight becomes too heavy, the beam will snap. If, on the other hand, the material has a high degree of elasticity, increasing weight would cause the beam to waffle, but it would not snap.

In Equation 1, performance or response time would be the dependent variable, $y$. The amount of vertical weight is the asymmetry $(a)$ parameter. The modulus of elasticity of the material is the bifurcation factor $(b)$, with low elasticity located at the high end of the bifurcation axis. Coping strategies, resilience, and anxiety levels would correspond to the bifurcation variable. According to Thompson (2010), resilience consists of both cognitive and emotional elements. Cognitive resilience includes preplanning, rehearsing, focusing, dividing tasks, prioritizing, and practicing. Emotional resilience would include the ability to recognize one's own emotions and the emotions of others and to act appropriately.

Anxiety can be a temporary result of stress, or it can be a long-term condition in the sense of a personality trait. Anxiety can have both positive and negative effects on performance in stressful conditions (Ein-Dor, Mikulincer, Doron, \& Shaver, 2010; Guastello, 2003; Guastello \& Lynn, 2010; Matthews \& Campbell, 2009). The negative impact of anxiety is that it leads to broken concentration, response delays, distortions of judgment, and errors; in this context, it might be 
regarded as a resilience deficit. The positive impact is that it is sometimes associated with greater vigilance and attentiveness to small cues that could signify a large impact. By having both positive and negative roles, anxiety functions as a bifurcation variable, although different people might adopt different individual responses to anxiety.

\section{Fatigue}

Fatigue is defined as the loss of work capacity over time for both cognitive and physical labor (Dodge, 1917; Guastello, 1995; Guastello \& McGee, 1987). Depletion of work capacity is typically assessed by a work curve that plots performance over time; there is a sharp drop in performance when fatigue sets in that is also coupled with a higher level of performance variability over time. Not everyone experiences a decline as result of the same expenditures, however. Some show an increase in physical strength akin to "just getting warmed up," whereas others show stably high or lower performance levels for the duration of the work period.

loteyko (1920) introduced a cubic polynomial function to account for the classic and more common work curve as well as all the other variations. The cubic function was essentially the cusp catastrophe model for fatigue (Guastello \& McGee, 1987) studied here (Figure 2). It has the same structure as defined in Equation 1. Work capacity is the dependent measure that displays two stable states.

Capacity and performance at a single point in time are not always easy to distinguish, but in principle, it is capacity that is subject to dramatic or small change over time. The total quantity of work done would be the main contributor to the bifurcation parameter; if the individual did not accomplish much in a fixed amount of time, there would be comparably little drain on work capacity. Those individuals who did could exhibit either positive or negative changes in work capacity.

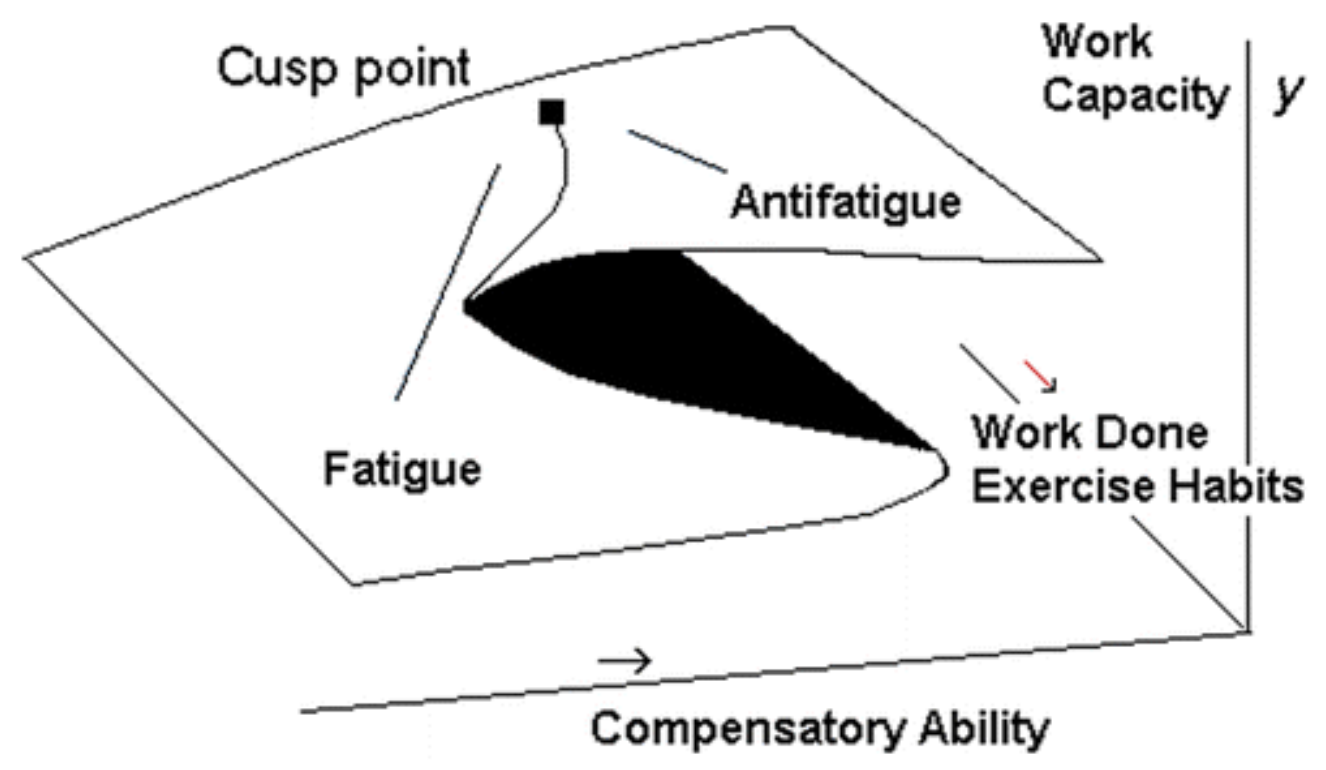

Figure 2. Two stable states of arm strength as a function of the amount of work actually performed and compensatory strength. 
The asymmetry parameter would be a compensatory strength measure. For instance, in Guastello and McGee (1987), laborers displayed differences in arm strength after approximately $2 \mathrm{hr}$ of standard mill labor tasks, which primarily demanded arm strength. Workers were measured on isometric arm strength and leg strength before and after the work session. Leg strength showed little change after the work session, which was not surprising, but it did act as a compensation factor for arm strength; those with greater leg strength experienced less fatigue in their arms.

Growing evidence from brain imaging data supports the principle of compensatory ability effects in cognition. Elderly people recruit more brain areas to perform some tasks compared with younger people, particularly if they are diagnosed with cognitive deficits (Drag \& Bieliauskas, 2010; ReuterLorenz \& Cappell, 2008; Schneider-Garces et al., 2009). It is unlikely that the patterns of additional circuit recruitment suddenly emerge when cognitive demands cross a threshold. It is more likely that they evolve as multiple ability areas are used together across the life span.

Current thinking is that working memory has several domain-specific modules (e.g., numerical, verbal, and spatial domains) that are hierarchically organized with a modicum of executive control over attention (Conway, Kane, Bunting, Hambrick, \& Engle, 2005; Logie, 2011). It is possible that memory modules are recruited as needed when demands increase or change. Functions that might be central to one task could be compensatory to another. Furthermore, variables that might permit elasticity in one context might be inert in another. Thus, the study by Guastello et al. (2011) and the present one involved speeded arithmetic and spelling tests to tap two domain-specific capacities that could play some role as compensation variables when performing those experimental tasks.

\section{Degrees-of-Freedom Principle}

Catastrophe models describe phase shifts that often arise from self-organizing dynamics (Guastello, 2005). Self-organizing dynamics typically take the form of information flows among the subsystems. The concept of degrees of freedom was first introduced in conjunction with physical movements (Bernstein, 1967; Marken, 1991; Rosenbaum, Slotta, Vaughn, \& Plamondon, 1991; Turvey, 1990) and explains how fixed and variable upper limits to cognitive channel capacity are both viable. In any particular complex movement, each limb of the body is capable of moving in a limited number of ways, and the movements made by one limb restrict or facilitate movement by other limbs. For this reason, we do not walk by stepping both feet forward simultaneously, for instance. More generically, degrees of freedom are the number of component parts, such as muscles or neural networks, that could function differently to produce the final performance result. The notion of internally connected nodes of movement is substantially simpler and more efficient than assuming that all elements of movement are controlled by a central executive function (Turvey, 1990).

When a movement is in its earliest stages of learning, the individual explores several optional combinations; but when learning consolidates, the movement combinations gravitate toward conserving degrees of freedom, which is essentially a path of least resistance (Hong, 2010). The gravitation is actually a self-organization dynamic. Residual variability in the movement persists, however, to facilitate new adaptive responses. Substantial changes in goals or demands produce a phase shift in the motor movements, which are observed as discontinuous changes in the sense of catastrophe models. Cognitive behaviors are thought to operate on similar principles with regard to stages of schematic development, the role of executive functions, and the principle of conserving 
degrees of freedom (Hollis, Kloos, \& Van Orden, 2009). Furthermore, cognition is often tied to action; the possible degrees of freedom span the whole perception-action sequence (Renaud, Chartier, \& Albert, 2009).

When workload exceeds a fixed upper limit of channel capacity, the discontinuity in performance would be the simple result of hitting a barrier. As such, there would be little room for the elasticity associated with bifurcation effects or variable upper limits. If variable upper limits were operating, however, the principle of conserving degrees of freedom would have a few implications: In the case of adding tasks or new demands to existing tasks, a change in one cognitive-behavioral motion would affect the other motions in the system or sequence. If it were possible to conserve degrees of freedom further, a phase shift in the cognition-action sequence would result in a catastrophic effect on performance. The bifurcation variables would predispose the individual to produce the appropriate adaptation or remain unchanged. For example, an increased demand for visual search could result in a shift from an exhaustive search to an optimized first-terminating strategy (Townsend \& Wenger, 2004).

In cases of fatigue, the increase in performance variability during the low-production period arises from an internal search for a possible reconfiguration of degrees of freedom (Hong, 2010). There are two plausible scenarios: According to the redistribution principle, the individual is searching for a lower-entropy means of accomplishing the same task or goal. If a loss of total entropy was occurring, however, the individual not only would be trying to regroup internal resources but also would be reducing responsiveness to the total complexity of task situations and demands, gravitating toward what amounts to the easier task options or situations or to simpler tasks.

\section{New Objectives}

In an earlier experiment (Guastello et al., 2011), undergraduates completed a nonverbal episodic memory task that had an automatically speeded component. Performance was measured across a 20min period along with measures of spelling and arithmetic ability and anxiety. Anxiety was thought to have a bifurcating effect on performance by interrupting performance on one hand but increasing vigilance on the other. Changes in task performance were characterized well by the catastrophe models. For buckling under workload, the epoch of maximum (speeded) performance was the asymmetry parameter; anxiety did not contribute to bifurcation as expected, however. For fatigue, the bifurcation factor was the total work accomplished, and arithmetic, a compensatory ability, was the asymmetry parameter. In both cases, the $R^{2}$ for the cusp was greater than $R^{2}$ for both alternative linear models.

The present study investigated fatigue and workload effects in a task that required pictorial memory that was activated by verbal cues. Possible compensation variables for fatigue involved arithmetic, spelling, and episodic memory ability. The workload manipulation involved three extra-task components: competition with another participant, incentives for better performance, and time pressure. Trait-type anxiety was tested as a bifurcation variable in the workload model again with the premise that it could be relevant if competition or other social interactions are part of the task experience. 


\section{Method}

\section{Participants}

The experimental participants were 130 undergraduates enrolled in psychology courses at a midwestern U.S. university. Another 151 undergraduates participated in a preliminary phase of the study that was designed to improve the reliability of the arithmetic and spelling measurements that were used in the main experiment. Their ages ranged from 18 to 20 years $(M=18.04)$; the population was $61 \%$ female. Participants in this human participants pool are routinely awarded credits toward their course grades based on the amount of participation time that is involved.

\section{Procedures}

The experiment was organized into two sessions. In the first session, the participants in the experiment performed the following sequence of activities: the spelling test (5 min), the arithmetic test $(5 \mathrm{~min})$, the anxiety test ( $3 \mathrm{~min}$ ), the episodic memory task ( $5 \mathrm{~min}$ ), the central experimental task (50 $\mathrm{min})$, the episodic memory task again, a parallel form of the spelling test, and a parallel form of the arithmetic test. Participants were counterbalanced for having taken the arithmetic test before spelling and vice versa and for which set of parallel forms was used the beginning and end of the session.

The episodic memory task was a computer-based game, MySimon (Neave, 2009). The game stimuli consist of a picture of a four-color geometric object, in which one of the colored areas lights up when a tone is played. The game begins with the presentation of one tone and one colored light. The participant clicks the same colored light with the mouse. The game continues with a sequence of two lights and tones, which the participant repeats. If the participant makes the correct response, the game continues with progressively longer sequences of lights and tones. The presentation speed for the lights and tones is progressively faster as well. A counter on the screen tells the participant how many points have been accumulated in an unbroken sequence of correct responses. If the participant makes an error, the system reverts to sequences of one tone and light and continues to expand the sequence again. Performance points for the experimental data were recorded as the number of correct responses within a fixed period of time. A screenshot from MySimon appears in Figure 3. 


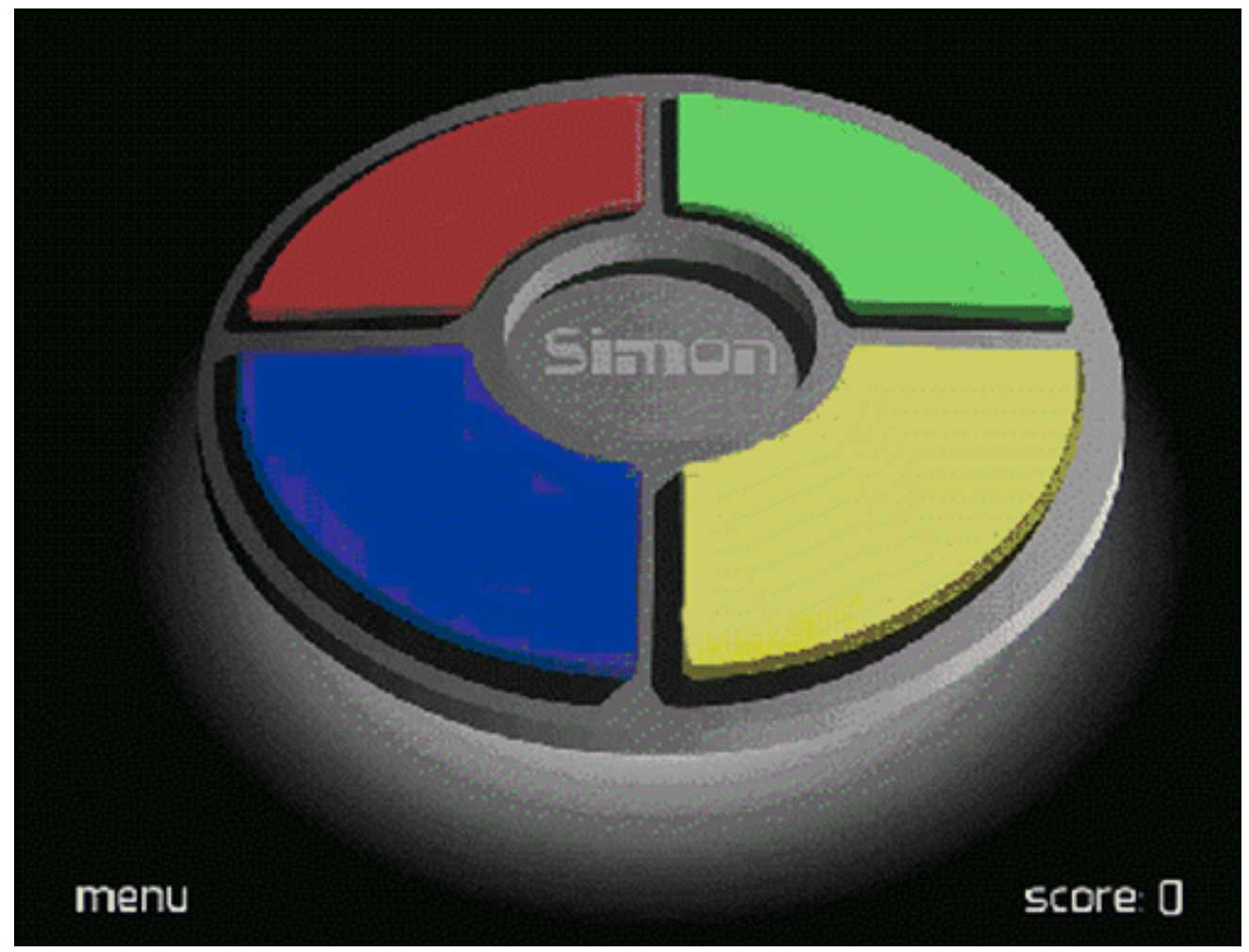

Figure 3. Screenshot of MySimon by Neeve (2009).

The main experimental task was I Spy (Wick \& Marzollo, 1995). For Session 1, participants played in the solitaire mode: They had 60 picture cards laid out on a table and selected a "riddle card" from a deck. The riddle was a verbal cue to four of the cards that they needed to identify from the table. The score was total number of picture cards that a participant could match with the riddle in a time interval.

Participants in Session 2 worked in pairs to play the game competitively. Pairs were assigned on the basis of convenience for the participants' schedules and not on the basis of any data collected in the earlier session. In the competitive mode, the picture cards were presented facedown. Each player drew a riddle from the deck. To begin the game, the younger player started first. The player turned over four cards to see whether any of them correspond to the riddle. If so, the player removed that card and continued by turning over another card and continued to do so if another match was made. If the player matched all four riddle elements, he or she selected another riddle card and continued; otherwise, it became the other player's turn. The winner was the player who made the most matches by the end of the 1-hr session.

Among the five experimental conditions in Session 2, four involved a $2 \times 2$ analysis of Incentive Conditions $\times$ Time Constraints. For incentives, participants were told that if they won the game session, they would get bonus credits for their participation. For time pressure, the participants were told that their turn was limited to $90 \mathrm{~s}$ (which was almost always the case). In the fifth condition, the participants who could not be paired with another participant played I Spy in solitaire mode again. 


\section{Measurements}

The arithmetic tests consisted of 19 items involving addition (two addends), subtraction, multiplication, and division. Addition, subtraction and multiplication items involved two- and threedigit numbers. Division items involved a three-digit dividend and a one-, two-, or three-digit divisor, with the instruction to carry out the calculation to two decimal places. Alpha values for internal consistency were .72 for Form $A(M=11.12, S D=3.06)$ and .69 for Form $B(M=11.34, S D=2.84)$ in the preliminary sample of 151 participants. The correlation between the two forms, which were presented in counterbalanced order, was .49 .

The spelling tests consisted of 50 items based on words that are commonly misspelled by adults (e.g., noose, schism, nautical, penalized, pneumatic). Target words were presented in a sentence. The respondent was instructed to circle the misspelled word and write the correct spelling in the answer space. Some sentences did not contain misspelled words, in which case the respondent was instructed to leave the answer space blank. Because the test was timed, some participants did not finish the test; their total scores included the correct blanks that immediately followed their last spelling correction. Alpha values for were .88 for Form $A(M=28.26, S D=8.38)$ and .89 for Form $B(M=33.24, S D=8.12)$ in the preliminary sample of 151 participants. The two forms were made equivalent by adding a constant of 5.0 to scores from Form A. The correlation between the two forms was 68 .

The anxiety test was a variation of Taylor Manifest Anxiety symptoms (Taylor, 1953) that was used in earlier research on cognitive workload and fatigue (Guastello et al., 2011). It consisted of 19 statements, such as "I have nightmares about my job or classes." The participant responded by checking Agree ( 2 points), ? ( 1 point), or Disagree (0 points). Some items were reverse scored ( $M=$ $12.84, S D=7.10, \alpha=.75)$.

MySimon produced two scores for each testing: (a) the total number of points earned in the 5-min period and (b) the peak scores that the participants obtained in their best run before making an error. Scores for the pictorial memory task (I Spy) were organized into 10-min intervals. For the fatigue analysis, the scores on the first 10 min were compared against the scores in the last $10 \mathrm{~min}$, with the scores in the middle $30 \mathrm{~min}$ used as the measure of intervening work accomplished. For the workload analyses, the total score from 50 min of Session 1 were compared against 50 min of Session 2.

The experimental manipulations in Session 2 produced two dichotomous variables for timed-untimed conditions and incentive conditions. Those two variables were tested as bifurcation effects in the cusp analysis for workload.

\section{Analyses}

The first analysis was an analysis of variance to determine whether there were any changes in the scores on the parallel forms that were attributed to administering arithmetic before spelling or vice versa. There were also simple $t$ tests to determine simple differences between the starting and ending measurements and an analysis of variance for the data in Session 2.

The cusp analyses were polynomial regression analogues of Equation 2: 


$$
\Delta z=\beta_{0}+\beta_{1} z_{1}^{3}+\beta_{2} z_{1}^{2}+\beta_{3} b z_{1}+\beta_{4} a,
$$

where $z$ was the dependent measure observed at two points in time, $b$ was the bifurcation variable, $a$ was the asymmetry variable, and all variables were transformed by location and scale before entering into the regression model (Guastello, 1995, 2011) and are thus designated as $z$ instead of $y$. Multiple variables could be entered as $b$ or $a$ and would have additional regression weights associated with them. The quadratic element is actually optional; its significance indicates that catastrophic shifts in one direction outnumber shifts in the opposite direction. If statistical significance was not obtained for all the important terms in the model, the quadratic term would be dropped.

$R^{2}$ for the cusp model was compared with $R^{2}$ for two linear comparison models:

$$
\begin{gathered}
\Delta y=\beta_{0}+\beta_{1} b+\beta_{2} a, \text { and } \\
y_{2}=\beta_{0}+\beta_{1} y_{1}+\beta_{2} b+\beta_{3} a .
\end{gathered}
$$

The linear models involve the same variables that are used as cusp control variables but without the nonlinear structures. Equation 3 describes a prediction of change in the dependent measure. Equation 4 describes the subsequent performance as a function of prior performance and the research variables. Ideally, the $R^{2}$ for the cusp models should exceed the $R^{2}$ for their linear counterparts.

The criteria for evaluating the models are whether all the parts of the model were identified, the model's accuracy, and how the model's accuracy compared with next-best alternatives. The critical parts of the model were the cubic term, the bifurcation variable, and the asymmetry variable. In the case of fatigue, the bifurcation variable would be the amount of work done between the two endpoints that were tested, and the asymmetry variable would be a compensatory ability. In the case of workload, the bifurcation variable would be some aspect of elasticity or resilience, and the asymmetry variable would be a manipulation of load level. Assuming the model is fundamentally correct and the usual sources of measurement and experimental error are within reason, $R^{2}$ will be higher to the extent that the full topological space defined by the model was represented in the data (Guastello, 2011).

If $R^{2}$ for the cusp exceeded $R^{2}$ for the linear difference model (Equation 2), then the cusp would explain changes in performance better than the linear model. If $R^{2}$ for the cusp exceeded $R^{2}$ for the pretestposttest linear model, then it is possible to conclude that the cusp was the dominant explanation for performance variance. If, on the other hand, $R^{2}$ for the pretest-posttest model exceeded $R^{2}$ for the cusp, then one concludes that the linear function for nonchange was a better description of the events in the data set than the cusp was.

\section{Results}

\section{Basic Statistics for Fatigue}

The means and standard deviations for the experimental variables appear in Table 1. There was a small but significant net improvement in both arithmetic and spelling scores between the beginning and end of the experiment. Analysis of variance was used to determine whether taking the spelling test before arithmetic or vice versa affected scores. Test order did not affect either set of scores. 
Table 1: Descriptive Statistics for Cognitive Measurements

\begin{tabular}{|l|l|l|l|l|l|l|l|}
\hline & Pretest & & & Posttest & & & \\
\hline Task & $M$ & $S D$ & & $M$ & $S D$ & $n$ & $t$ \\
\hline Arithmetic & 11.69 & 2.04 & 12.04 & 2.54 & 130 & $5.44^{*}$ \\
\hline Spelling & 30.97 & 9.67 & 33.39 & 8.29 & 130 & $4.10^{*}$ \\
\hline Episodal memory total & 39.55 & 5.69 & 52.46 & 5.61 & 127 & $5.28^{*}$ \\
\hline Episodal memory peak & 12.47 & 3.12 & 11.87 & 2.94 & 127 & $-0.87^{*}$ \\
\hline Pictorial memory & 13.01 & 5.89 & 59.33 & 26.12 & & \\
\hline
\end{tabular}

${ }^{*} p<.001$.

There was an improvement in the episodic memory task before and after the main task but a small decrease in the peak scores (Table 1). This pair of findings indicated that the participants were changing their strategy for scoring points in the task by trying to score points in smaller chunks rather than pushing their memory spans to the limit.

There was a sharp improvement in the pictorial task across the five 10-min intervals (Figure 4), $F(4$, $128)=246.24, p<.0001$. Trend analysis showed a significant linear, $F(1,128)=468.43, p<.0001$, and a significant cubic trend, $F(1,128)=8.71, p<.01$. There was also a significant $(p<.01)$ increase in variance in the pictorial task performance from the first to the second, $F(128,128)=5.10$, and from the second to the third time interval, $F=2.401$.

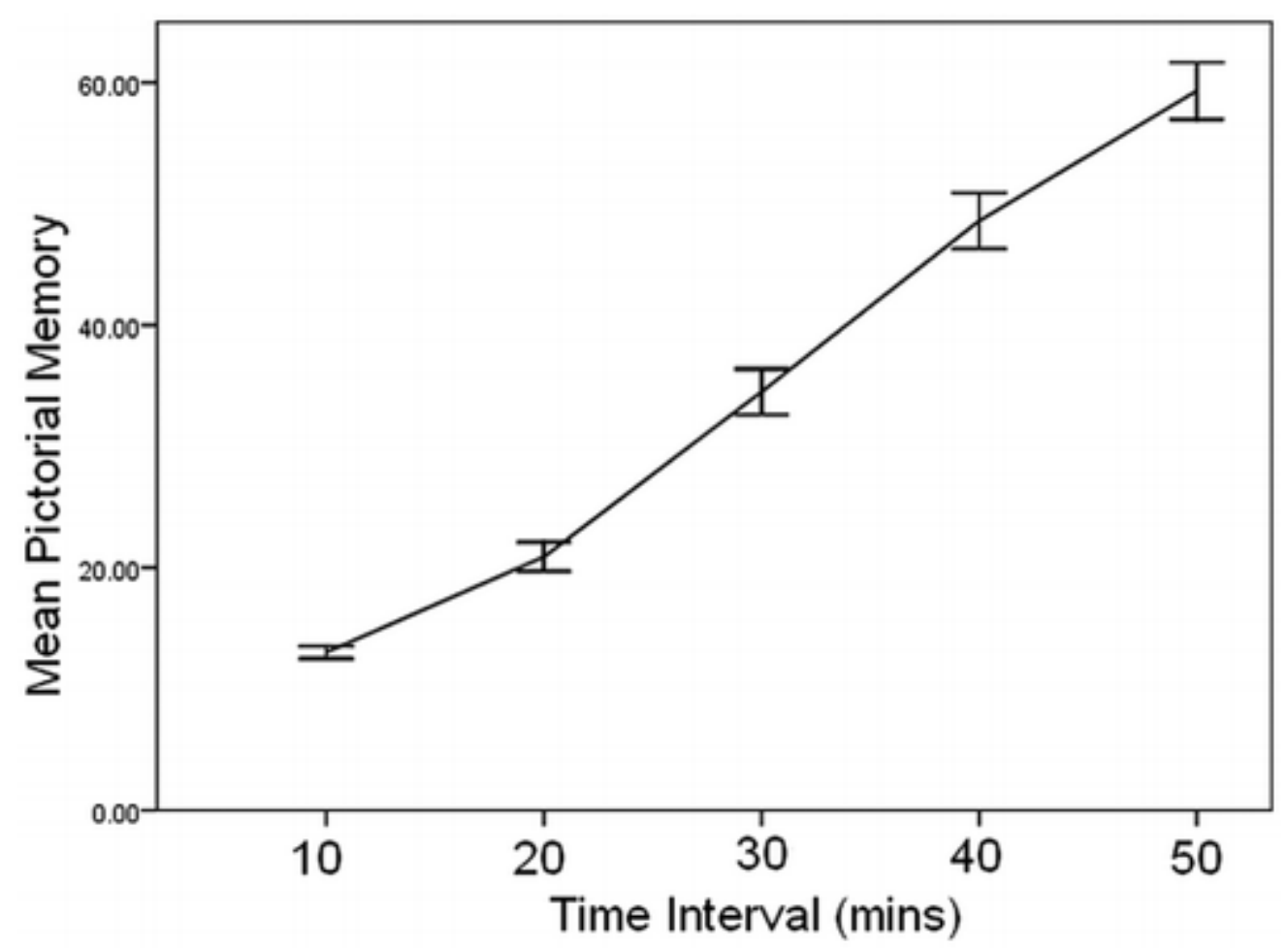

Figure 4. Trend analysis for performance on the pictorial memory task performance. 


\section{Cusps for Fatigue}

Regression models for the cusps were determined with the use of both backward elimination and stepwise procedures. The patterns of significant regression weights were not appreciably different for the two procedures. Thus the stepwise solutions were adopted for comparison with the linear models. Table 2 shows the comparisons of $R^{2}$ coefficients and the $F$ tests for Equations 2, 3, and 4 . Table 3 lists the regression weights for the cusp models and their significance tests.

Table 2: Summary of $R^{2}$ and $F$ Tests for Cusp and Linear Models

\begin{tabular}{|c|c|c|c|c|c|c|}
\hline & $\begin{array}{l}\text { Cusp } \\
\text { Stepwise }\end{array}$ & & $\begin{array}{l}\text { Linear } \\
\text { Difference }\end{array}$ & & $\begin{array}{l}\text { Linear Pretest- } \\
\text { Posttest }\end{array}$ & \\
\hline Task & $R^{2}$ & $\begin{array}{l}\text { Adjusted } \\
R^{2}\end{array}$ & $R^{2}$ & $\begin{array}{l}\text { Adjusted } \\
R^{2}\end{array}$ & $R^{2}$ & $\begin{array}{l}\text { Adjusted } \\
R^{2}\end{array}$ \\
\hline \multicolumn{7}{|l|}{ Fatigue } \\
\hline Arithmetic & .232 & .232 & .007 & .000 & .423 & .399 \\
\hline Spelling & .218 & .199 & .020 & .000 & .547 & .548 \\
\hline $\begin{array}{l}\text { Episodal } \\
\text { total }\end{array}$ & .297 & .297 & .155 & .127 & .111 & .074 \\
\hline $\begin{array}{l}\text { Episodal } \\
\text { peak }\end{array}$ & .392 & .383 & .041 & .048 & .067 & .036 \\
\hline Pictorial & .523 & .528 & .484 & .463 & .590 & .570 \\
\hline \multicolumn{7}{|l|}{ Workload } \\
\hline \multirow[t]{2}{*}{ Pictorial } & .530 & .515 & .050 & .020 & .128 & .091 \\
\hline & $d f$ & $F$ & $d f$ & $F$ & $d f$ & $F$ \\
\hline \multicolumn{7}{|l|}{ Fatigue } \\
\hline Arithmetic & 1,124 & $37.45 * * *$ & 4,121 & 0.20 & 5,120 & $17.61 * * *$ \\
\hline Spelling & 3,122 & $11.36^{* * *}$ & 4,121 & 0.89 & 5,120 & $28.97^{* * *}$ \\
\hline $\begin{array}{l}\text { Episodal } \\
\text { total }\end{array}$ & 1,124 & $52.38^{* * *}$ & 4,121 & $5.56^{* * *}$ & 5,120 & $3.01^{* *}$ \\
\hline $\begin{array}{l}\text { Episodal } \\
\text { peak }\end{array}$ & 2,123 & $39.73 * * *$ & 3,122 & 1.75 & 4,121 & $2.17^{*}$ \\
\hline Pictorial & 4,124 & $34.02 * * *$ & 5,123 & $23.10 * * *$ & 6,122 & $29.25^{* * *}$ \\
\hline \multicolumn{7}{|l|}{ Workload } \\
\hline Pictorial & 3,94 & $35.34^{* * *}$ & 3,94 & 1.66 & 4,93 & $3.42^{*}$ \\
\hline
\end{tabular}

$* p<.10{ }^{* *} p<.05 . * * * p<.001$.

Table 3: Regression Weights and Significance Tests for Cusp Models for Fatigue 


\begin{tabular}{|c|c|c|c|c|c|}
\hline & b & $t$ & b & $t$ & $r$ \\
\hline \multicolumn{6}{|l|}{ Task } \\
\hline \multicolumn{6}{|l|}{ Arithmetic } \\
\hline Cubic & -0.329 & -0.64 & -0.482 & $17.02^{* * * *}$ & $-.463^{* * *}$ \\
\hline Quadratic & -0.220 & -0.40 & & & $-.457 * * * *$ \\
\hline$z_{1} \times$ Episodal Total & 0.036 & 0.31 & & & $-.278 * * *$ \\
\hline$z_{1} \times$ Pictorial & 0.054 & 0.53 & & & $-.192^{* *}$ \\
\hline Spelling & 0.111 & 1.36 & & & .077 \\
\hline \multicolumn{6}{|l|}{ Spelling } \\
\hline Cubic & 0.935 & $1.94 *$ & 1.004 & $2.17^{* *}$ & $-.290 * * * *$ \\
\hline Quadratic & -1.272 & $-2.47^{* *}$ & -1.391 & $-3.01 * * *$ & $-.332^{* * * *}$ \\
\hline$z_{1} \times$ Episodal Total & -1.116 & -0.94 & & & $-.317^{* * * *}$ \\
\hline$z_{1} \times$ Pictorial & 0.037 & 0.33 & & & $-.221^{* *}$ \\
\hline Arithmetic & 0.219 & $2.63^{* * *}$ & 0.219 & $2.66^{* * *}$ & $178^{* *}$ \\
\hline \multicolumn{6}{|l|}{ Episodal memory peak } \\
\hline Cubic & 0.600 & $0.07 * *$ & 0.604 & $2.13 * *$ & $-.552^{* * * *}$ \\
\hline Quadratic & -1.194 & $-3.85^{* * *}$ & -1.194 & $-4.20 * * * *$ & $-.609 * * * *$ \\
\hline$z_{1} \times$ Pictorial & 0.009 & 0.08 & & & $-.215^{* *}$ \\
\hline Arithmetic & 0.007 & 0.09 & & & -.016 \\
\hline Spelling & 0.050 & 0.68 & & & .099 \\
\hline \multicolumn{6}{|l|}{ Episodal memory total } \\
\hline Cubic & 0.497 & $1.74^{*}$ & & & $-.491 * * * *$ \\
\hline Quadratic & -0.931 & $-3.25 * * *$ & -0.545 & $-7.24 * * * *$ & $-.545^{* * * *}$ \\
\hline$z_{1} \times$ Pictorial & -0.128 & -1.35 & & & $-.402 * * * *$ \\
\hline$z_{1} \times$ Episodal Peak & -0.044 & -0.53 & & & $-.255^{* * *}$ \\
\hline Arithmetic & -0.031 & -0.41 & & & -.045 \\
\hline Spelling & -0.048 & -0.62 & & & -.134 \\
\hline \multicolumn{6}{|l|}{ Pictorial memory } \\
\hline Cubic & 0.816 & $2.76^{* * *}$ & 0.800 & $2.76 * * *$ & $-.517 * * * *$ \\
\hline Quadratic & -2.165 & $-6.27 * * * *$ & -2.185 & $-6.38 * * * *$ & $-.540 * * * *$ \\
\hline$z_{1} \times$ Pictorial Mid & 0.917 & $6.65 * * * *$ & 0.931 & $6.83^{* * * *}$ & $-.271 * * *$ \\
\hline Episodal total & -0.045 & -0.58 & & & $-.188 * *$ \\
\hline Episodal peak & -0.149 & $-1.87 *$ & 0.168 & $2.63^{* * *}$ & .130 \\
\hline Arithmetic & -0.53 & -0.83 & & & -.112 \\
\hline Spelling & -0.60 & 0.93 & & & .029 \\
\hline
\end{tabular}

${ }^{*} p<.10 .{ }^{* *} p<.05 .{ }^{* * *} p<.01 .{ }^{* * * *} p<.001$.

We constructed the linear comparison models by entering all the variables that were part of the cusp model simultaneously. Their regression weights are listed in Table 4. In all cases, the cusp model was a better explanation of change scores than was the linear difference model. The results for the different tasks varied, however, in the regression weights that were significant and in how well they compared to the linear pretest-posttest model. 
Table 4: Regression Weights and Significance Tests for Linear Models for Fatigue

\begin{tabular}{|c|c|c|c|c|c|c|}
\hline & Difference & & & $\begin{array}{l}\text { Pretest- } \\
\text { Posttest }\end{array}$ & & \\
\hline Task & $\beta$ & $t$ & $r$ & $\beta$ & $t$ & $r$ \\
\hline \multicolumn{7}{|l|}{ Arithmetic } \\
\hline Episodal peak & 0.033 & 0.52 & .039 & 0.042 & 0.51 & .070 \\
\hline Episodal total & -0.008 & -0.08 & -.032 & -0.015 & -0.19 & -.059 \\
\hline Pictorial & 0.051 & 0.52 & .056 & 0.056 & 0.76 & .120 \\
\hline Spelling pretest & 0.35 & 0.52 & .069 & 0.096 & 1.36 & $.229 * * *$ \\
\hline Arithmetic pretest & & & & 0.616 & $8.77^{* * * *}$ & $.643^{* * * *}$ \\
\hline \multicolumn{7}{|l|}{ Spelling } \\
\hline Episodal peak & 0.030 & 0.28 & .062 & -0.035 & -0.48 & -.055 \\
\hline Episodal total & -0.100 & -0.96 & -.104 & -0.060 & -0.85 & -.013 \\
\hline Pictorial & -0.066 & -0.70 & -.209 & 0.041 & 0.62 & .138 \\
\hline Arithmetic pretest & 0.121 & 1.35 & .128 & 0.176 & $2.83 * * *$ & $.295^{* * * *}$ \\
\hline Spelling pretest & & & & 0.682 & $10.74 * * * *$ & $.730 * * * *$ \\
\hline \multicolumn{7}{|l|}{ Episodal peak } \\
\hline Pictorial & -0.178 & $-1.98 * *$ & $-.160 *$ & 0.041 & 0.44 & .122 \\
\hline Spelling pretest & 0.127 & 1.40 & .100 & 0.050 & 0.55 & .036 \\
\hline Arithmetic pretest & -0.027 & -0.30 & -.017 & -0.003 & -0.04 & .016 \\
\hline $\begin{array}{r}\text { Episodal peak } \\
\text { pretest }\end{array}$ & & & & 0.241 & $2.58^{* *}$ & $.249 * * * *$ \\
\hline \multicolumn{7}{|l|}{ Episodal total } \\
\hline Episodal peak & 0.384 & $4.34 * * * *$ & $.364 * * * *$ & 0.039 & 0.34 & $-.187 * *$ \\
\hline Pictorial & -0.075 & -0.84 & .025 & -0.098 & -1.07 & $-.157^{*}$ \\
\hline Spelling pretest & -0.096 & -1.11 & -.135 & -0.054 & -0.60 & -.029 \\
\hline Arithmetic pretest & -0.43 & -0.51 & -.045 & -0.042 & -0.48 & -.051 \\
\hline $\begin{array}{r}\begin{array}{r}\text { Episodal total } \\
\text { pretest }\end{array} \\
\end{array}$ & & & & 0.321 & $2.93^{* * *}$ & $.307^{* * * *}$ \\
\hline \multicolumn{7}{|l|}{ Pictorial } \\
\hline Pictorial mid & 0.644 & $9.42 * * *$ & $.680 * * * *$ & 0.729 & $10.21 * * * *$ & $.755^{* * * *}$ \\
\hline Episodal peak & 0.095 & 1.14 & $.305^{* * * *}$ & 0.100 & 1.34 & $.326 * * * *$ \\
\hline Episodal total & -0.72 & 0.89 & $-.252 * * *$ & -0.064 & -0.88 & $\begin{array}{l}- \\
.244 * * *\end{array}$ \\
\hline Spelling pretest & -0.28 & 0.41 & .099 & 0.020 & 0.33 & .110 \\
\hline Arithmetic pretest & -0.42 & -0.64 & -.008 & -0.007 & -0.11 & .045 \\
\hline Pictorial pretest & & & & -0.021 & 0.31 & $.400 * * * *$ \\
\hline
\end{tabular}

$* \mathrm{p}<.10 .{ }^{*} \mathrm{p}<.05 . * * * \mathrm{p}<.01 . * * * * \mathrm{p}<.001$.

The only significant term in the cusp model for arithmetic was the cubic effect; the linear pretestposttest model was a better explanation of the data overall. There were three significant elements in cusp model for spelling - the cubic term, the quadratic term, and arithmetic (compensatory ability) but the bifurcation effects for total work done on the intervening tasks were not significant. The linear pretest-posttest model was a better explanation of the data overall, however.

The cusp models for the total score and peak score on episodic memory were both more accurate than their counterpart linear models. The cubic and quadratic terms were significant in both cases, but the 
bifurcation effects for total work done on the intervening tasks were not significant, nor were there any compensatory abilities identified.

A complete cusp model was obtained for the pictorial memory task. The significant elements were the cubic and quadratic terms, the total amount of work that transpired between the pretest and posttest (bifurcation), and the peak score on the episodic memory task (compensatory ability). The pretestposttest linear model accounted for $7 \%$ more variance, however, suggesting that the participants were not fatigued enough to combat the strong practice effect inherent in this task.

\section{Workload}

The workload analyses did not include the participants who could not be matched with a competitor. A $2 \times 2$ ANOVA showed that participants in the incentive conditions produced more work than did those in the nonincentive conditions, $F(1,94)=12.87, p<.001$. The main effect for time pressure was not significant, $F(1,94)=0.12$. There was a significant interaction (Figure 5$)$, however, between time pressure and incentives, $F(1,94)=5.32, p<.05$. The time constraint had a negative impact on performance in the incentive condition and a positive impact in the no-incentive condition.

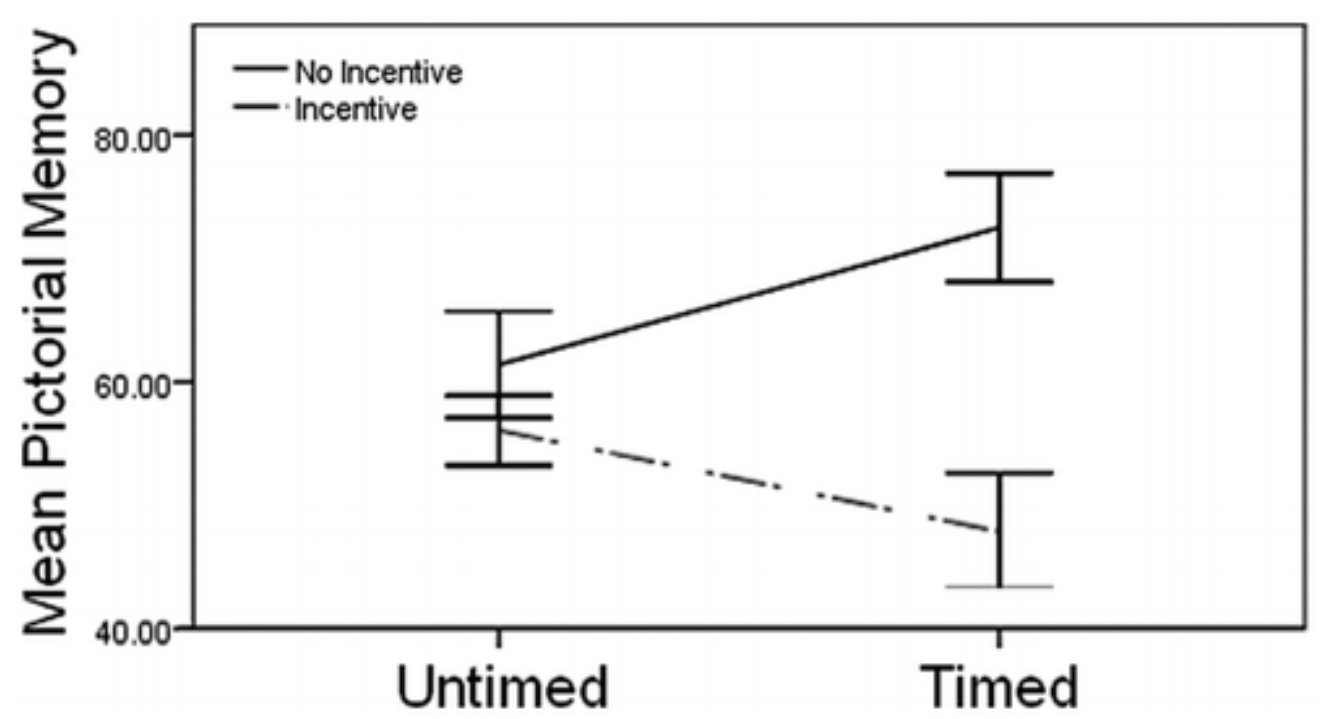

Figure 5. Interaction between timed and incentive conditions on pictorial memory task performance.

The cusp model was more accurate than either of the two linear models. Significant weights (Table 5) were obtained for the cubic effect, anxiety as a bifurcation variable, and incentive condition as the asymmetry variable that added load.

Table 5: Regression Weights and Significance Tests for Cusp and Linear Models for Workload

\begin{tabular}{|l|l|r|}
\hline Model & \multicolumn{1}{|c|}{ ? } & $t$ \\
\hline Cusp & & $6.49 * * * *$ \\
\hline Cubic & -0.537 & $-3.19 * * * *$ \\
\hline$z_{1} \times$ Anxiety & -0.232 & $t$ \\
\hline
\end{tabular}




\begin{tabular}{|l|l|c|}
\hline Incentive & -0.184 & $-2.19^{* *}$ \\
\hline Linear difference & & -0.36 \\
\hline Anxiety & -0.037 & $-2.03^{* *}$ \\
\hline Incentive & -0.215 & -0.04 \\
\hline Timed & -0.004 & \\
\hline Linear pretest-posttest & & -1.08 \\
\hline Anxiety & -0.107 & $-3.06^{* * * *}$ \\
\hline Incentive & -0.314 & -0.07 \\
\hline Timed & -0.007 & 1.37 \\
\hline Pictorial pretest & 0.134 & \\
\hline
\end{tabular}

$* * p<.05 . * * * * p<.001$.

\section{Discussion}

Two catastrophe models were proposed and tested for separating the effects of cognitive workload and fatigue. Evaluating the models simultaneously requires an experimental design that included manipulations of load along with the extended time on task needed to produce fatigue. Because the cusp models accommodate improvements in performance as well as declines, the fatigue model can separate learning from fatigue effects that are occurring simultaneously.

\section{Fatigue}

The main pictorial memory task produced the best results for fatigue. The cubic, bifurcation, and asymmetry variables were all present. The bifurcation variable was the amount of work done in the time interval between the two endpoints. The compensatory ability was the peak score on the episodic memory task.

The cusp was more accurate than the linear difference model but not as accurate as the linear pretestposttest model, however. The ancillary analyses showed that there was a strong practice or learning effect in the pictorial task whereby participants were able to memorize the stimuli and response combinations; it was not possible to do so in the episodic memory task, which produced higher $R^{2}$ than did the two linear models in the previous study (Guastello et al., 2011) and in this study also. The cubic trend over time and the increased variance (Figure 3) added support for the cusp model, however. Variance is expected to increase as the participant's performance moves from the cusp point to the unfolded portion of the surface where the stable states are located.

In retrospect, it appeared that the fatigue effect for the pictorial memory task was not strong enough to compensate for the learning effect. Future research should be designed for longer work periods to produce greater fatigue. Dropping practice trials is not always a viable option when the learning effect carries through an extensive portion of the work time, as it did in the pictorial task.

The fatigue cusp for episodic memory met the accuracy criterion, and it did contain the cubic function. However, it did not display the needed control variables, although it did so in the earlier experiment (Guastello et al., 2011), in which the intervening work period was more episodic memory. The tentative conclusion is that fatigue effects are more prominent when the intervening amount of work is done on the target task instead of an alternative task. 
The degrees-of-freedom principle was observed in the episodic memory task. The participants appeared to shift their cognitive strategies between the two 5-min sessions. They started by putting stronger effort into long memory runs (peak score) to collect game points. In the second session, they reduced their peak score but picked more "low-hanging fruit" from shorter runs, thereby increasing their scores overall.

\section{Workload}

The first workload manipulation, which applied to all participants, was the shift from playing the game in solitaire mode to playing against a competitor. The competition mode also put a greater demand on memory because the game pieces were face down and the player needed to remember where all the cards were located. The second and third manipulations were the experimental conditions for incentives and time limits. Although the incentive may seem trivial in the real world, extra-credit points are meaningful to college students. The effect of time limits was apparent in the ANOVA, but they did not have a unique effect in the cusp model.

Overall, the cusp model was more accurate than the alternative linear models. It contained a cubic effect, anxiety was the bifurcation effect, and the incentive condition was the additional load factor. Another lesson learned was that anxiety worked in this experiment but not in the previous study, which involved an individual task. Apparently, anxiety becomes relevant in some working conditions and not in others, which also suggests that different resilience strategies could matter at other times.

\section{Future Research}

New experimental tasks should be sufficiently fatiguing so as to counteract learning or practice effects. They should also introduce greater elements of realism into the tasks. The tasks and variables examined thus far were chosen to exemplify abstract principles of workload and fatigue. Now that the efficacy of the experimental paradigm is established, it is possible to introduce new complications and interpret the results. One might use the dual-task methodology, whereby one task soaks up channel capacity and the second task is the target of analysis, or combine tasks with same or different resource demands as defined in Wickens's (2008) model. Physical activity beyond the simple clicking of a computer mouse should be included also.

The full definition of cognitive strategies is still needed and requires further exploration of some outstanding questions concerning task selection and task sequencing by the operator. The idea that fatigue on a target task is more likely when the intervening work period is spent on the target task than on another task should be examined more systematically. Questions regarding the optimal sequencing of tasks could include how an operator might choose to organize a group of tasks that need to be performed. The principle of degrees of freedom could be exploited further to define how an operator might perform a particular task that could have several mental components and to assess tasks that involve controlled versus automatic processes.

\section{Key Points}

- The two cusp catastrophe models offer a theoretical solution for separating fatigue, workload, and learning or practice phenomena. 
- Models were supported by experimental data and extend previous findings for other types of tasks concerning the role of abilities that compensate for fatigue and anxiety as a bifurcation variable in workload dynamics.

- Experimentally induced fatigue needs to be stronger than the learning effect that also transpires over time.

- Time on the target task produces more fatigue on the target task than does time on other demanding tasks that are fatiguing in their own right.

\section{References}

Ackerman, P. L. (Ed.). (2011). Cognitive fatigue. Washington, DC: American Psychological Association.

Alves, E. E., Kelsey, C. M. (2010). Combating vigilance decrement in a single-operator radar platform. Ergonomics in Design, 18(2), 6-9.

Bernstein, N. (1967). The coordination and regulation of movements. Oxford, UK: Pergamon.

Conrad, R. (1951). Speed and load stress in a psychomotor skill. British Journal of Industrial Medicine, 8, 1-7.

Conway, A. R. A., Kane, M. J., Bunting, M. F., Hambrick, D. Z., Engle, R. W. (2005). Working memory span tasks: A methodological review and user's guide. Psychonomic Bulletin \& Review, 12, 769-786.

Dodge, R. L. (1917). The laws of relative fatigue. Psychological Review, 24, 89-113.

Drag, L. L., Bieliauskas, L. A. (2010). Contemporary review 2009: Cognitive aging. Journal of Geriatric Psychiatry, 23, 75-93.

Ein-Dor, T., Mikulincer, M., Doron, G., Shaver, P. R. (2010). The attachment paradox: How can so many of us (the insecure ones) have no adaptive advantages. Perspectives on Psychological Science, 5, 123-141.

Guastello, S. J. (1995). Chaos, catastrophe, and human affairs: Applications of nonlinear dynamics to work, organizations, and social evolution. Mahwah, NJ: Lawrence Erlbaum.

Guastello, S. J. (2003). Nonlinear dynamics, complex systems, and occupational accidents. Human Factors in Manufacturing, 13, 293-304.

Guastello, S. J. (2005). Statistical distributions and self-organizing phenomena: What conclusions should be drawn? Nonlinear Dynamics, Psychology, and Life Sciences, 9, 463-478.

Guastello, S. J. (2011). Discontinuities: SETAR and catastrophe models with polynomial regression. In Guastello, S. J., Gregson, R. A. M. (Eds.), Nonlinear dynamical systems analysis for the behavioral sciences using real data (pp. 251-280). Boca Raton, FL: CRC Press/Taylor \& Francis.

Guastello, S. J., Boeh, H., Shumaker, C., Schimmels, M. (2011). Catastrophe models for cognitive workload and fatigue. Theoretical Issues in Ergonomics Science, 12. Advance online publication.

Guastello, S. J., Lynn, M. (2010, March). Catastrophe model of the accident process, safety climate, and anxiety. Paper presented at the 4th International Nonlinear Science Conference, Palermo, Italy.

Guastello, S. J., McGee, D. W. (1987). Mathematical modeling of fatigue in physically demanding jobs. Journal of Mathematical Psychology, 31, 248-269. 
Hancock, P. A., Desmond, P. A. (Eds.). (2001). Stress, workload, and fatigue. Mahwah, NJ: Lawrence Erlbaum.

Hancock, P. A., Warm, J. S. (1989). A dynamic model of stress and sustained attention. Human Factors, 31, 519-537.

Harris, W. C., Hancock, P. A., Harris, S. C. (2005). Information processing changes following stress. Military Psychology, 17, 115-128.

Hendy, K. C., Liao, J. Q., Milgram, P. (1997). Combining time and intensity in assessing operator information load. Human Factors, 39, 30-47.

Hockey, G. R. J. (1997). Compensatory control in the regulation of human performance under stress and high workload: A cognitive-energetical framework. Biological Psychology, 45, 73-93.

Hollis, G., Kloos, H., Van Orden, G. C. (2009). Origins of order in cognitive activity. In Guastello, S. J., Koopmans, M., Pincus, D. (Eds.), Chaos and complexity in psychology: The theory of nonlinear dynamical systems (pp. 206-242). New York, NY: Cambridge University Press.

Hong, S. L. (2010). The entropy conservation principle: Applications in ergonomics and human factors. Nonlinear Dynamics, Psychology, and Life Sciences, 14, 291-315.

loteyko, J. (1920). La fatigue [Fatigue] (2nd ed.). Paris, France: Flammarion.

Kantowitz, B. H. (1985). Channels and stages in human information processing: A limited analysis of theory and methodology. Journal of Mathematical Psychology, 29, 135-174.

Logie, R. H. (2011). The functional organization and capacity limits of working memory. Current Directions in Psychological Science, 20, 240-245.

Lorist, M. M., Faber, L. G. (2011). Consideration of the influence of mental fatigue on controlled and automatic cognitive processes. In Ackerman, P. (Ed.), Cognitive fatigue (pp. 105126). Washington, DC: American Psychological Association.

Marken, R. S. (1991). Degrees of freedom in behavior. Psychological Science, 2, 86-91.

Matthews, G., Campbell, S. E. (2009). Sustained performance under overload: Personality and individual differences in stress and coping. Theoretical Issues in Ergonomics Science, 10, 417-443.

Neave, P. (2009). MySimon. Retrieved from http://www.freegames.ws/games/kidsgames/simon/mysimon.htm

Ralph, J., Gray, W. D., Schoelles, M. J. (2010). Squeezing the balloon: Analyzing the unpredictable effects of cognitive workload. Proceedings of the Human Factors and Ergonomics Society, 54, 299-303.

Renaud, P., Chartier, S., Albert, G. (2009). Embodied and embedded: The dynamics of extracting perceptual visual invariants. In Guastello, S. J., Koopmans, M., Pincus, D. (Eds.), Chaos and complexity in psychology: The theory of nonlinear dynamical systems (pp. 177205). New York, NY: Cambridge University Press.

Reuter-Lorenz, P. A., Cappell, K. A. (2008). Neurocognitive aging and compensation hypothesis. Current Directions in Psychological Science, 17, 177-182.

Rosenbaum, D. A., Slotta, J. D., Vaughn, J., Plamondon, R. (1991). Optimal movement selection. Psychological Science, 2, 92-101.

Schneider-Garces, N. J., Gordon, B. A., Brumback-Peltz, C. R., Shin, E., Lee, Y., . . Fabiani, M. (2009). Span, $\mathrm{CRUNCH}$, and beyond: Working memory capacity and the aging brain. Journal of Cognitive Neuroscience, 22, 655-669.

Sheridan, T. B. (2008). Risk, human error, and system resilience: Fundamental ideas. Human Factors, 50, 418-426. 
Taylor, J. A. (1953). A personality scale of manifest anxiety. Journal of Abnormal and Social Psychology, 48, 285-290.

Thom, R. (1975). Structural stability and morphegenesis. New York, NY: Benjamin-AddisonWesley.

Thompson, H. L. (2010). The stress effect: Why smart leaders make dumb decisions-and what to do about it. San Francisco, CA: Jossey-Bass.

Townsend, J. T., Wenger, M. J. (2004). A theory of interactive parallel processing: New capacity measures and predictions for a response time inequality series. Psychological Review, 30, 708-719.

Turvey, M. T. (1990). Coordination. American Psychologist, 45, 938-953.

Wick, W., Marzollo, J. (1995). I spy memory game: A game of picture riddles. Montclair, NJ: Briarpatch.

Wickens, C. D. (2008). Multiple resources and mental workload. Human Factors, 50, 449-455.

Zeeman, E. C. (1977). Catastrophe theory: Selected papers 1972-1977. Reading, MA: AddisonWesley. 